\title{
Influencing Consumers to Choose Environmentally Friendly Offerings: Evidence from Field Experiments
}

\begin{abstract}
The objective of this article is to examine a set of ways to influence consumer behavior toward making more environmentally friendly choices. We conducted three different studies to investigate (1) what consumers think would influence their behavior, (2) how several question-based verbal influence strategies nudge consumer behavior in one direction or another, and (3) how question-based written influence strategies influence consumer behavior. The findings reveal a discrepancy between what consumers think would influence behavior and what actually does influence it. In addition, under all verbal and written experimental conditions, influence strategies led to consumer change toward environmentally friendly offerings compared with alternative non-environment friendly offerings. The discussion highlights possible explanations for the results, managerial implications, the study's limitations, and suggestions for future research, with a special emphasis on research into factors that can change consumer behavior.
\end{abstract}

Key words: Field experiments, Influence, Retailing, Environmentally friendly products, Nudging, Question-behavior effects 


\section{Influencing Consumers to Choose Environmentally Friendly Offerings: Evidence from Field Experiments}

\section{Introduction}

Over the past decade, a variety of new environmentally friendly options have become available for consumers interested in contributing to sustainable development by purchasing eco-labeled products and services. However, research indicates that consumers do not purchase these products enough to have positive long-term effects on the planet. For example, MacGillivray (2000) found that sustainable initiatives like ecolabeled products and services, as well as offerings with an ethical and/or fair-trade label, often show low market shares of approximately one percent. Vermeir and Verbeke (2005) found similar behavioral patterns, while Gupta and Ogden (2006) found that only a few consumers who showed pro-environmental attitudes regarding recycling, concern about car pollution, and willingness to pay more for environmentally friendly offerings actually translated these attitudes into corresponding behaviors. Despite retailers' attempts to perceptually position eco-labeled products in appealing and attentive ways, consumer purchases continue to follow traditional patterns (Anselmsson \& Johansson, 2007). The disparity between purchase intentions and purchase behavior was highlighted in a recent article by Grimmer et al. (2015), and similar observations have been made by consumer agencies around the world (e.g., Mintel, 2006; Swedish Consumer Agency, 2006). The present article investigates ways to influence consumers to change their behavior and increase their purchase of environmentally friendly offerings in grocery stores.

A common method of influencing individuals' behavior (in order, for example, increase the use of safety belts, the use of condoms, or to help people quit smoking) has 
been to use information campaigns (e.g., de Bro et al., 1994; Robertson et al., 1974; Siegel \& Biener, 2000; Wilson et al., 1994). Such campaigns have used information in attempts to persuade individuals to behave in ways that are deemed better for themselves and for society at large. Such studies rest on the notion that attitudes will shape behavioral intentions and behaviors (Ajzen, 1991). Unfortunately, social psychology studies over the years have consistently found attitudes to be poor predictors of actual market behavior (for example, Ajzen, 2001), a finding that has repeatedly been shown to be valid for green consumption as well (see, for example, Peattie, 2010). In line with this, a leading grocery store in Sweden reported that only 20 percent of its customers actually choose to buy environmentally friendly (for example, eco-labeled) offerings over non-labeled competitive brands. From an environmental perspective, the low volume of sales of environmentally friendly offerings presents a challenge where research could play an important and advising role in informing how more consumers could be influenced to collectively engage in behaviors that will help the environment.

Therefore, the objective of this study is to investigate possible ways to influence consumer behavior in order to make it more environmentally friendly. This article applies theories that studies in areas other than ecological food products have shown to have a stronger and more effective direct influence on human behavior than information campaigns (Cialdini, 2008; Thaler, 2015, Ajzen, 2001). The principal contribution in the article is that theories of influence are applied in a retail setting where the questionbehavior effect (Sprott et al., 2006) is used to nudge consumers towards the behavior of buying environmentally friendly offerings. Thus, consumer behavior is influenced to increase the purchase of environmentally friendly groceries by means of question-based 
nudges, in the real-life context of a supermarket. We conducted a total of three studies on the impact of green nudges.

\section{Theoretical Framework}

How can behavior be influenced in an easy but profound way? Several studies have shown that merely asking a question about a particular behavior can influence behavior related to the question (Chandon et al., 2005, Janssen et al., 2008; Sprott et al., 2006; Söderlund \& Mattsson, 2015). This source of behavioral influence is referred to as "the question-behavior effect" (Sprott et al., 2006).

One explanation of why this works concerns a situation in which a respondent is asked about their intention; pre-existing intentions become more accessible in memory, which leads to increased strength in respondents' intentions and, in the next step, affects behavior (Chandon et al., 2005). Another explanation indicates that simply asking about intentions could signal that someone cares about the respondent's views, which has a positive charge that may carry over to attitudes related to performing the behavior (Chandon et al., 2005). From a broader perspective, both of these explanations assume the form of semantic priming. Priming increases accessibility of the associated content and the likelihood that the associated content will be used in a subsequent cognitive operation increases (Janiszewski \& Wyer, 2014). This response pattern has been shown in several studies. For example, Braun (1999) used advertising as a prime to influence a remembered experience of a low-quality product. Participants read promotional material that asked them to imagine a positive taste experience, which led to an increased accessibility of content that changed the recollection of the actual taste experience (that is, from bad to good taste). Berger and Fitzsimons (2008) used semantic priming when they asked shoppers to list eight types of candy/chocolate on 
the day before Halloween. The dominant color of Halloween (orange) primed brands with which this color was associated (for example, Reese's) and increased the likelihood that these brands would be mentioned. Légal et al. (2012) found that priming the goal "to trust" led to greater acceptance of a persuasive message and an increased intention to engage in the advocated behavior. To sum up, in terms of our purpose of influencing consumer behavior towards environmentally friendly purchases, the question-behavior effect and its underlying account of semantic priming stand out as useful and will therefore be applied as framework in our research.

Building on priming and the question-behavior effect, interpersonal processes such as commitment and visibility also appear as powerful ways to influence people to a certain desired behavior (Cialdini, 2008; Fombelle et al., 2015; Griskevicious et al., 2010, He et al., 2012; Hill et al., 2016, Motes \& Woodside, 2001; Spangenberg et al., 2006). To illustrate, an individual's behavior in a typical study is shaped by information given about the behavior of those around them. Influencing people in this deliberate manner, through techniques that shape human behavior in a desired way, is commonly referred to as 'nudging' (Thaler, 2015; Thaler \& Sunstein, 2008). Nudging implies that positive reinforcement and/or indirect suggestions are being used to achieve non-forced compliance, which influences the likelihood of desired motives in a more effective way than traditional instructions, legislations, or enforcements (Thaler \& Sunstein, 2008). For example, nudging implies influencing groups of people in a desired direction by giving small but definitive hints. In line with this, Thaler and Sunstein (2008) showed that individuals are more likely to take the stairs than the elevator when told that "most people choose to take the stairs". Nudging theorizes that rather simple techniques can have a significant influence on an individual's behavior. A small adjustment in how an activity is phrased can influence the subsequent behavior of others. For example, Huguet 
and Régner (2009) found that boys do better than girls in a technical drawing class called 'geometry', but that girls do equally well or better when the class is called 'drawing'. Whenever small pieces of information are given, as in the studies above, a question that indirectly primes a subsequent behavior is involved. These types of influence strategies, where informational phrases are used, appear promising in light of the challenge of changing consumer behavior toward making environmentally friendly choices. Below, we identify four influence strategies and describe their conceptual background. All four strategies build on semantic priming and the question-behavior effect. The question-behavior effect leads to our first hypothesis, after which we present four influence strategies and their respective hypotheses, using the question-behavior effect. For an overview, see Table 2.

\subsection{The question-behavior effect}

As noted above, the question-behavior effect occurs when asking an individual a certain question leads to changes in that person's subsequent behavior. The effect has proven so strong that it works even for non-normative behaviors such as illegal drug use (Williams et al., 2006). Research regarding the question-behavior effect has typically dealt with questionnaire items, particularly intentions questions (such as "How likely is it that you will do X?") (Chandon et al., 2005; Söderlund \& Mattson, 2015; Williams et al., 2006). Conversely, the question-behavior effect was examined in the present studies under the conditions where a retail employee, or a sign within the store, asks a customer a question about their future behavior. Furthermore, we compared the effect of various influence scripts that rely on a question-based nudge. According to previous research, a simple question about a future behavior should guide future behavior. Therefore, based on the literature on the question-behavior effect, we expect that when a supermarket 
customer is asked a question containing information about the choice between environmentally friendly versus non-environmentally friendly offerings, this will activate dormant intentions that choosing environmentally friendly options is important. This leads us to our first hypothesis:

H1: A question that informs a customer that they can choose between environmentally friendly products and non-environmentally friendly ones will increase the sales of environmentally friendly products compared to baseline sales in the store.

\subsection{Signaling}

One interesting way to influence people is through the signals individuals send to others. Signaling implies that an individual's behavior communicates the kind of a person they are, or wish to be perceived as (Baca-Motes et al., 2013; Griskevicius et al., 2010). Baca-Motes et al. (2013) reported that when hotel guests receive a lapel pin to signal their commitment to the environment, they are more than 25 percent more likely to hang up at least one towel for reuse. Thus, the number of reused towels by consumers who are sent a small signal about being environmentally friendly increases by more than 40 percent. Signaling has also been studied within the context of advertisements, where signals are believed to be responsible for unobservable cues of, for example, product quality to consumers (e.g., Kirmani \& Rao, 2000). Individuals are also sensitive to external signals when the individual is the sender of the signal. This is shown in studies of how uniforms create certain types of organizational behavior (Pratt \& Rafaeli, 1997). This leads us to our second hypothesis: 
H2: A question that informs a customer that a front-line employee is present where environmentally friendly products are offered will increase the sales of environmentally friendly products compared to the store's baseline sales.

\subsection{Labeling}

Labeling is a nudging technique that emerged as a result of Tybout and Yalch's (1980) research. Labeling entails classifying, or giving someone a describing characteristic, with the intention that the individual's actions will be consistent with that classification or characterization. Using labeling as a technique implies a heightened self-perception of a certain behavior, which enhances the likelihood that the label-consistent behavior will be displayed later. Labeling functions mainly because individuals desire to act in ways that are congruent with an established idea or self-image, or with the label (Cialdini \& Goldstein, 2004). Research shows that activation of cognitive and perceptual representations often leads to corresponding overt behavior (Dijksterhuijs \& Knippenberg, 1998). For example, Dijksterhuijs and Knippenberg (1998) found that activating the mental representation of a certain social group (for example, professors) led to behaviors corresponding with specific attributes of that social group (such as intelligence) being displayed. Thus, an indirect prime triggered performance of behaviors that were aligned with schemas previously known by the participant. Tybout and Yalch (1980) found that citizens labeled as having an 'above-average probability of voting' were more likely to actually vote in an election a week later than those citizens labeled as having an 'average probability of voting'. This leads us to our third hypothesis: 
H3: A question that informs a customer that they appear interested in environmentally friendly products will increase the sale of environmentally friendly products compared to the store's baseline sales.

\subsection{Price}

According to a literature review by Auger et al. (2003), consumers repeatedly state that price is an important choice criterion for them. In one study, consumers indicated that they would pay $\$ 1$ more for a $\$ 20$ item manufactured under 'good' conditions. Freestone and McGoldrick (2008) also found that price is important for customers considering ethical and environmentally friendly purchases. Zeithaml (1988) argued that the relationship between price, quality, and value has always been pivotal in understanding consumer choice; also, when consumers are asked about their purchase preferences, they repeatedly mention price as an important decision criterion (Campbell, 2007; Krishna, 1992). Consistent with our framework, price has also been shown to prime consumers (Herr, 1989). Finally, Young et al. (2012) showed that monetary incentives help consumers concentrate their limited efforts on green purchases. In general, ecologically labeled offerings are more expensive than their nonecologically labeled counterparts. As consumers are aware of the customary difference in price, our study examines whether eliminating this price difference affects their choice (Arnot, Boxall and Cash, 2006; Loureiro et al, 2002). This leads us to our fourth hypothesis:

H4: A question that informs a customer that there is no price difference between environmentally friendly and non-environmentally friendly products will increase the sales of environmentally friendly products compared to the store's baseline sales. 
The research hypotheses presented above employ a framework in which consumers are nudged with a question that is expected to guide subsequent behavior. An important question is whether to forward this question by way of a retail employee verbally or by way of a written sign. Most marketers have failed to acknowledge the relevance of the source, whether it is human or nonhuman (Campbell, 2007). However, psychological studies have shown that the source (personal vs. non-personal) actually influences evaluations (Moon \& Conlon, 2002). For example, evaluations of information from humans are perceived as more favorable when the outcome is good and less favorable when the outcome is perceived as negative or bad. Individuals respond more effectively to humans than to nonhumans,. This means that when good information comes from a human, a decision-making bias appears that, for example, significantly reduces discomfort (Moon \& Conlon, 2002). In regard to the question-behavior effect, Spangenberg et al. (2008) and Williams et al. (2006) suggested that verbal questions can guide behavior in an effective way. However, Chandon et al. (2005) found that written information also shapes respondents' behavior in the desired direction. Due to the mixed findings regarding the influence of the source, we also examine the effectiveness of the influence strategies when communicated verbally (by an employee) compared to (nonhuman) written signs. From a managerial perspective, the choice between employees verbally asking questions or using signs is important and motivates our last research question. We have not presented a hypothesis in relation to this question because the literature does not give us enough advice on the direction.

\section{Three Empirical Studies}

The objective of this article is to examine several strategies for influencing consumer behavior toward more environmentally friendly choices. Therefore, we designed three 
different studies: an introductory pre-study regarding what consumers perceive would influence their behavior; Study I, which assesses how various verbal influence strategies actually change consumer behavior; and Study II, which deals with how written influence strategies actually change consumer behavior.

\section{Pre-Study}

\subsection{Pre-Study: Perceptions about the likelihood of influencing consumer behavior} In general, what do people think would influence their purchasing behavior? Although predicting what would change or direct one's own behavior is difficult (Milgram, 1975), it remains common practice in social psychology. We conducted a pre-study at a branch of one of Sweden's leading grocery stores, ICA Maxi, in a medium-sized Swedish city, with the goal of understanding how consumers perceive the likelihood that they will change their behavior toward purchasing more environmentally friendly offerings compared with competing non-environmentally friendly ones. If consumers were positive about changing their behavior, breaking old habits and creating new behaviors would proceed relatively easily. However, it is more realistic to assume that consumers do not generally want to be influenced or persuaded to change. Research shows that attempts at persuasion are likely to activate personal skills to cope by defying the intentions of the attempt (Friestad \& Wright, 1994). Therefore, surveying how consumers perceive attempts to change their behavior may provide us with important knowledge about how effective our strategies to influence are likely to be.

\subsubsection{Method}


We designed a survey consisting of six questions about how participants perceived the likelihood that consumers in general would change their behavior and administered the survey to 200 customers who had just completed their shopping at a grocery store (ICA Maxi). Three of the questions were based on the influence strategies identified in the previous theory section: (1) Are consumers' choices (of product) affected if other people observe what they choose? (Signaling); (2) If consumers label someone as environmentally friendly (for example), would that affect their choice of products? (Labeling); and (3) Are low prices an important reason why consumers choose a certain offering? (Price).

Personal bias creates a risk of third-person effects (Davison, 1983). Therefore, the likelihood of someone else changing is often a better predictor of behavior than asking about the individual's own behavior. For this reason, all questions regarding likelihood of changing behavior applied to 'people in general'. We also asked two other questions:

(4) Do consumers perceive that environmentally friendly offerings are important? (5)

To what extent do they actually purchase environmentally friendly offerings?

For all six items, we used a response scale ranging from 1

(unlikely/unimportant/seldom) to 10 (very likely/very important/always).

\subsubsection{Results and Discussion}

In order to understand how consumers perceived the effectiveness of changing consumer behavior, we compared the influence strategies with each other. Repeated ANOVA measures revealed significant differences $[F(2,396) 182.777, p \leq .01]$ between the three influence strategies. Follow-up Bonferroni correction of pairwise comparisons showed that participants perceive price as more influential than signaling and signaling 
as more influential than labeling. All comparisons were significant $(p=.01)$. See Table 1 for the means and standard deviations for all three influence strategies.

\section{>> Insert Table 1 about here $<<$}

In order to analyze a potential discrepancy between how much importance participants place on environmentally friendly purchases and their actual behavior, we compared participants' perceptions of these two measures. A paired samples t-test indicated a significant gap $t[(198) 9.802, p=.09]$ between consumers' attitudes toward the importance of purchasing environmentally friendly offerings $(M=7.02, S D=2.45)$ and their actual purchase behavior $(M=5.81, S D=2.59)$.

The results of our pre-study indicate that, according to the beliefs of consumers, the easiest way to influence consumer behavior would be price reductions for environmentally friendly offerings. The other influence strategies only have an average level of effectiveness, clustered around five on the 10-point scale. Study I also revealed evidence of an inconsistency between how people think about environmentally friendly consumption and their own behavior. This finding is corroborated by previous consumer research regarding the attitude-behavior gap (Vermeir \& Verbeke, 2006; d'Astous \& Legendre, 2009).

As noted above, existing research underlines that asking questions about a behavior may also provoke that particular behavior (Chandon et al., 2005; Spangenberg et al., 2003; Sprott et al., 2006). Therefore, survey data on how consumers perceive they would behave must be validated by true observations from real behavior. In order to understand what factors influence change in consumer behavior, it is necessary to conduct a field study in which actual purchases are being made. 


\section{Study I}

\subsection{Study I: Verbal influence strategies to change consumer behavior}

The data that we collected and analyzed in the pre-study relies on consumers' perceptions of how they believe people in general behave and think. In order to investigate whether there is an actual effect and not just a perceived one, we used the identified influencing strategies as the independent variables to perform a field experiment in the same grocery store (ICA Maxi). We sought to determine whether the influence strategies actually motivate consumers to change their behavior as the participants in the pre-study had predicted. The aim of Study 1 was to examine how the influence strategies communicated by a front-line employee affect consumers' decisions when purchasing bananas. There were several reasons why we chose bananas as the central product. First, fruits are among the grocery products that have the strongest impact on the environment (Cohen, 2009; Fogelberg, 2008). Second, bananas are among the most frequently purchased grocery items. Third, the choice between an eco-labeled and non-eco-labeled banana was particularly significant in the store where the field experiment was conducted because the two competing types of bananas were displayed right next to each other, with equal space and arrangements in the middle of the fruit department, and looked virtually identical.

\subsubsection{Method}

\subsubsection{Sample and setting}

Over three days, 400 grocery consumers were randomly assigned to one of four groups. The data was collected between 10 a.m. and 4 p.m., Tuesday through Thursday, in October 2013. The experimental condition was changed for every $30^{\text {th }}$ participant in order to counterbalance the effects of time of day and day of the week. The study was 
conducted as a field experiment and the participants engaged in normal purchasing behavior that they would undertake naturally, unaware that they were taking part in an experiment (Verbeke et al., 2016).

\subsubsection{Variables}

A confederate front-line employee was instructed to stand approximately 10 meters (32 feet) in front of the banana section and read one of four different influence scripts when a customer approached the displays of ecologically labeled bananas and regular bananas. For all of the experimental conditions, customers were exposed to a specific sentence, or "verbal influence script", about their subsequent behavior. These scripts represented the independent variable. See Table 2 for the specific verbal influence scripts and their respective theoretical backgrounds.

\section{> Insert Table 2 about here $<<$}

As shown in Table 2, the question-behavior condition is built up by a question about whether the customer is going to buy bananas or not. In the Signaling group, the consumer signaled by making their choice of banana right in front of a front-line employee (that is, they selected either eco-labeled or non-eco-labeled bananas). In the Labeling condition, consumers were labeled as 'environmentally friendly' in order to see whether such a label affected their choice of bananas. Lastly, consumers in the Price group were informed that in this particular grocery store the price of ecologically labeled bananas was the same as for the competing non-ecologically labeled ones (that is, there was no price difference). 
In addition to the four experimental groups, we also included sales data from the previous week as a baseline. As a result, we had four experimental groups (Questionbehavior, Signaling, Labeling, Price) and one baseline (sales data from the week before the experiment started) condition.

\subsubsection{Procedure}

Approximately 10 meters away from the fruit and vegetable section, a front-line grocery employee approached customers with a direct question: "Are you going to buy bananas today?" If a customer replied in the affirmative, the front-line employee used one of the four influence strategies to continue the conversation with the consumer. When using the 'signaling' influence script, another front-line employee stood next to the banana display so that the consumer understood that an employee would notice which choice of bananas the consumer made.

\subsubsection{Results}

In order to test the hypotheses regarding the impact of the four verbal influence strategies, we conducted a series of $\mathrm{Chi}^{2}$ tests on the proportion of eco-labeled bananas. Firstly, in order to test H1, we compared the proportion of participants in the Questionbehavior condition who chose eco-friendly bananas with the baseline (sales data). The results confirmed $\mathrm{H} 1$ and showed that the mere presence of the front-line employee pointing out the different banana alternatives increased the proportion of choices significantly in favor of eco-labeled bananas (from 25 percent to 40 percent, $p=.01$ ). Secondly, to test H2, we compared the proportions of chosen eco-friendly bananas amongst the participants in the Signaling condition with the participants in the Question-behavior condition. The results confirmed H2 and showed that participants 
who made the choice right in front of the frontline employee made significantly $(p<.01)$ more (68 percent) eco-friendly choices than the participants in the Question-answer condition (40 percent). Finally, both $\mathrm{H} 3$ and $\mathrm{H} 4$ were confirmed because 76 percent of the participants in the both the Labeling and the Price conditions made eco-friendly choices, which is significantly more than both the Question-answer condition $(p<.01)$ and the Signaling condition $(p=.03)$.

\section{>> Insert Figure 1 about here $<<$}

\section{Comparison between the pre-study and Study I}

Comparing the survey data $(n=200)$ presented in pre-study with actual consumer behavior (Study I) reveals some interesting results. Unsurprisingly, participants in the pre-study identified price as a strong determinant of choice. However, contrary to the results of the survey, labeling is not the least influential strategy; the field experiment (Study I) shows the effect of labeling to be equally as strong as that of price.

\subsubsection{Discussion}

Our results provide a compelling answer to the question of whether consumer behavior can be influenced. The field experiment shows that all four verbal influence scripts are significantly better at influencing choices than the baseline data. A potential explanation for these results is that the consumers in our study simply have positive attitudes, since behavioral change is naturally easier to accomplish if individuals already have attitudes aligned with the desired behavior. It is plausible that habitual behavior may guide consumers and hinder them from behaving consistently in line with their attitudes. The front-line employees' in-store interactions with these retail consumers 
appear to remind consumers of their own attitudes, and therefore provide the rationale to align their behavior accordingly. This is in line with the theoretical idea of semantic priming described in the theory section.

It may be difficult to implement these results in actual retail stores due to the cost of having front-line employees positioned solely to communicate with customers. Years of experience in retail stores suggest that marketing managers resort to using signs instead. Therefore, we continue with another study to investigate the effects of written influence scripts (rather than verbal) to determine whether the effects found in Study I still apply.

\section{Study II}

\subsection{Study II: Influence strategies of signs to change consumer behavior}

Again in partnership with the grocery store ICA Maxi, we conducted another field experiment to examine how written influence strategies (through signs) affected consumers' purchase decisions to select environmentally friendly offerings in preference to competing, non-environmentally friendly ones, again focusing on bananas. Because previous research confirms that asking questions about future behaviors leads to an increase in the performance of socially normative behaviors, even when it comes to written questions, we expected that written influence strategies would also lead to an increased amount of choices of environmentally friendly labeled bananas. However, Sorensen (2009) reported that shoppers do not see most in-store communications, both promotional and corporate. This point motivates an investigation of the persuasive effect of written signs and makes it interesting to compare the outcome of Study II with that of Study I. 


\subsubsection{Method}

\subsubsection{Sample and setting}

Over three days, retail grocery consumers $(n=400)$ were randomly assigned to one of four groups. Three of the groups were exposed to a sign conveying one of the influencing messages (see Table 3) placed in the middle of the banana display. The participants in the fourth group were not shown any sign; the choices of these consumers were noted and used as a baseline (observation). The reason for the change of baseline from sales data (in Study I) to observational data (in Study II) was to make the baseline even more comparable to the other experimental groups. The data was collected between 10 a.m. and 4 p.m. from Tuesday through Thursday. The experimental condition was changed for every $25^{\text {th }}$ participant to counterbalance the effects of time of day and day of the week. Again, the study was a natural field experiment.

\subsubsection{Variables and Procedure}

Signs for the field experiment were specifically constructed for the purpose of changing consumer behavior. Three different influence strategies were used to entice customers when they approached the stand on which ecological and regular bananas were displayed. Apart from the usage of signs instead of frontline employees, the main difference between this study and the previous one was the exclusion of the questionbehavior script, as it was not possible to mimic this in text. Table 3 shows the independent variables used in Study 2, how they were operationalized, and their respective theoretical backgrounds.

\footnotetext{
>> Insert Table 3 about here $<<$
} 
For all experimental conditions, customers were exposed to a sign containing a specific sentence (that is, the written influence strategy) that was placed on the stand where the ecological and regular bananas were displayed. Each of the written signs corresponded to one of the experimental groups and represented the independent variable. In addition to the three experimental conditions, a pure observation condition was added. A research assistant standing in the background recorded each customer's choice of banana during the three experimental conditions, as well as during the baseline condition. Each sign was placed between the displays of the two types of bananas. As in Study I, the consumer's choice represented the dependent variable of the experiment. For signaling, the research assistant was positioned next to the banana display so that consumers would have a sense that someone was actually observing their choices.

\subsubsection{Results}

$\mathrm{Chi}^{2}$ tests on the proportion of eco-labeled banana purchases show the impact of signs on consumer behavior. All three types of signs (Signaling, Labeling, and Price) significantly increased the proportion of eco-labeled bananas chosen $(p s<.01)$ compared with the baseline (observation). This again confirms $\mathrm{H} 2, \mathrm{H} 3$, and $\mathrm{H} 4$ (see Figure 2 for proportions of ecological choices under the different conditions), although there is no significant difference among the three types of sign.

\section{>> Insert Figure 2 about here $<<$}

\subsubsection{Comparison between Studies I and II}


As mentioned earlier, we examined differences in consumer behavior the influence of front-line employees' verbal interactions and that caused by the influence of signs. A chi ${ }^{2}$ tests showed that the overall proportion of participants who chose eco-labeled bananas when exposed to the verbal influence (Signaling, Labeling, or Price) of front-line employees (73 percent) was significantly larger $(p<.01)$ than the proportion of participants who choose eco-labeled bananas under the three signage conditions (Signaling, Labeling, or Price) (49 percent).

\subsubsection{Discussion}

The field experiment in Study II clearly shows how the effect of signs can lead to behavioral change, and that all written scripts are significantly more influential than the baseline (observation) group. A possible simple explanation for these results is that the consumers in our study have positive attitudes, which enabled them to change their regular behavior relatively easily.

The outcome of Study II is interesting in light of what other researchers have concluded regarding written communication in stores. Scamell-Katz (2012) concluded that consumers avoid reading signs when they are inside stores; similarly, Sorensen (2009) stated that shoppers do not see most in-store communication, either promotional or corporate. Study II showed that when signs are written in a way that engages the consumer - that is, via information posed to them - written signs have an influencing effect on consumers.

\section{General Discussion}

\subsection{Summary of main findings}


The objective of this research was to investigate a set of ways to influence consumer behavior toward more environmentally friendly choices. In three studies, we examined

(a) what consumers think would influence consumer behavior; and (b) how various verbal or written influence strategies, in terms of questions asked to consumers, actually affect consumer behavior. Our findings reveal a discrepancy between what consumers think should influence behavior and what actually does influence behavior. In addition, under all experimental conditions, both verbal and written, influence strategies in which consumers were nudged with a question increased the choice of environmentally friendly offerings.

Many studies in the fields of marketing and psychology use undergraduates in laboratory studies as participants in order to understand a business or societal challenge (Henrich et al., 2010). Researchers such as Cialdini (2009), Baca-Motes et al. (2013), Levitt and List $(2007,2009)$ and Pham (2013) have highlighted the need for field experiments that yield results that represent actual consumer behavior that can be easily interpreted or extrapolated to real situations. The three studies in the present article address this need and contribute to an understanding of how consumer behavior in a real retail store can be nudged to improve the establishment of a more sustainable society. Below, we outline some possible explanations for the results and address managerial implications. We also discuss the limitations of the studies and suggest areas for further research into what may spur pro-environmental behavior among consumers.

\subsection{The impact of nudging}

Individuals engage in many automatic behaviors without a great deal of thought or attention to them (Bargh \& Ferguson, 2000). In one illuminating study (Langer, Blank, \& Chanowitz, 1978), individuals were asked to write things down automatically while 
simultaneously engaging in another task that requires attention, but were unable to recall the words they had just written down, despite being certain they had written something. This is relevant because from that study we can assume that, during grocery shopping, consumers are somewhat mindlessly daydreaming about other things.

Therefore, although consumers may have pro-environmental attitudes and be in favor of eco-labeled and locally produced offerings, they may function with automatic cognition and behavior while shopping and fail to notice environmentally friendly offerings. This is a possible explanation for why environmentally friendly offerings are still consumed at fairly low levels, and may also explain why both the verbal and written questions influenced consumers in our studies. That is, when consumers are confronted by a question (either verbally or in text) situated exactly where they make their choices, their inclination to daydream is disturbed. Thus, they are reminded, by the nudging question, of their pro-environmental attitudes and may find it easier to make the behavioral choice that aligns with those attitudes.

Moreover, our two studies using verbal influence or written influence strategies as independent variables resulted in interesting differences. Although both studies showed that these independent variables had significant effects, the verbal questions were more effective in influencing behavior. Thus, the output of Studies I and II indicates that a verbal prompt from a front-line employee has a greater impact than a written sign. This indicates that verbal prompts may also be preferable for influencing pro-environmental behaviors other than those made on the floor of the store, such as recycling or reducing food waste. However, when a consumer has financial constraints, and as indicated by our Study II, text may also produce behavioral change. In any event, the effectiveness of verbal questions in relation to text-based questions should be seen in the light of previous research on service encounters, which suggests that humans are sensitive to 
other humans in social encounters - in the sense that event small details in employee behavior (such as smiles, greetings, and eye contact) can have a powerful impact on customers (Söderlund, 2016; Sutton \& Rafaeli, 1996).

Our results appear to be in keeping with existing theories of why nudging of the type assessed in the present studies has an impact on consumer behavior. First, several previous studies have materialized the question-behavior effect (Chandon et al., 2005, Janssen et al., 2008; Sprott et al., 2006; Söderlund \& Mattsson, 2015) while dealing with behaviors other than those related to environmentally friendly choices. Second, labeling rests on the theoretical notion that we seek to behave in ways that reflect how others perceive us, especially when these perceptions are positive (Tybout \& Yalch, 1980). Third, signaling has roots in evolutionary behavior, in which the signals that individuals send are important status communicators (Griskevicious et al., 2012). Finally, as our pre-study confirms, price is an important purchase criterion, because saving money shows that a person is economically prudent. Thus, the results of our field experiments confirm the validity of previous findings in the context of environment-labeled groceries in retail stores.

\subsection{Implications for influencing consumer behavior}

Our findings offer practical information about how influence strategies can be used to nudge green consumer behavior in a socially desirable way. More specifically, our results suggest that retailers wishing to influence individuals' behavior can use the influence strategies of question-behavior, signaling, and labeling to "green nudge" consumers' behavior. These strategies can also be used by actors other than retailers, as has already been shown. In the United Kingdom, for example, a governmental institution employs a similar type of nudging strategies as those described in the present article in 
order to influence human behavior into making better decisions from an individual and societal point of view (Halpern, 2015). Considering the need to encourage

environmentally friendly behavior, our results are promising and we believe that they can be generalized to situations in which consumers already have positive attitudes toward changing their behavior, but have yet to actually change it. However, both retail managers and other actors applying nudging-based strategies should be aware of the criticism that exists with respect to the use of nudging; some critics consider it to be a form of subtle manipulation that can violate the autonomy of the person being subjected to the nudging (Wilkinson, 2013).

\subsection{Other variables that can influence environmentally friendly behavior}

A wider look into how to change consumers' behavior reveals that there are alternatives to the nudging influence strategies used in this article, such as branding, imitation, and habits. In terms of branding, Arnot, Boxall and Cash (2006) tested whether consumers would alter their purchasing behavior when given the opportunity to distinguish ethically labeled products from alternatives (as in the present article). In a field experiment with a university coffee vendor, prices were adjusted for a freshbrewed fair-trade-certified coffee and a similar tasting alternative. Examining sales on different days, the researchers concluded that demand for fair trade coffee was less sensitive to price than for the alternative coffee. Another study by Hiscox and Smyth (2006) found similar results.

In terms of imitation, when individuals assume that the actions of others are the correct behavior to perform, this is often referred to in terms of social proof (Cialdini, 2008). Social proof implies that people use the actions of others as guidelines to conform to in a given situation. In terms of people imitating other peoples' pro-environmental 
behavior, Nolan et al. (2008) found that when group behavior is presented as a social proof to inform individuals of how other people in the neighborhood were successful in managing energy conservation, this information led to more consumers imitating a similar behavior (that is, energy conserving). This effect is now a commonly used retail advertising strategy in which signs are used to inform consumers that a certain product is a best-seller (or similar).

Finally, influencing consumer behavior is ultimately about breaking habits and future studies could investigate techniques to influence and measure consumer habitual decisions (Duhigg, 2014). Sociocultural movements that involve, for example, peer pressure or word of mouth (e.g., McCabe \& Ricciardelli, 2005; Hartline \& Jones, 1996), or the recent popularity of gamification, are other important means of achieving consumer change (Fogg, 2002). It is important for researchers and/or policy makers who are trying to change the behavior of consumers or citizens to study the effect of these approaches.

\subsection{Limitations and suggestions for future research}

Our studies have certain limitations that can be addressed by future research. We believe that future studies are needed in order to understand how consumers can act to redress the discrepancies between their attitudes and behaviors through self-regulated behavioral change. As revealed by the pre-study, consumers are rather unaware of how their behavior is affected by various influences in their lives. In addition, future research could examine behavioral change when attitudes are negative, rather than mildly positive as in this study. Our research does not provide any answers regarding the power of the influence strategies when consumers do not want to change their behavior. Nor was it possible to collect any demographic or financial information from the 400 
consumers in the experiments. Consequently, there is a risk that the time of the day when the experiments were run could have attracted people who might have been easier to convert. In a similar way, Stolle and Micheletti (2005) showed that women are more likely to support and participate in politicized consumption than men. The same pattern was also found in Hainmueller and Hiscox's (2012) study, in which female shoppers were found more likely to choose fair-trade-labeled products. The studies in the present article are limited because they did not examine how demographic data such as gender or time of the day affected the results. To address these shortcomings in the future, a Latin squares experimental design should be used (Lindstrom et al., 2016). 


\section{References}

Ajzen, I. (1991). The theory of planned behavior. Organizational Behavior and Human Decision Processes, 50(2), 179-211.

Ajzen, I. (2001). Nature and operation of attitudes. Annual Review of Psychology, 52(1), $27-58$

Anderson, L., Ostrom, A. L., Corus, C., Fisk, R. P. Gallan, A. S., Giraldo, M., Mende, M. Mulder, M., Rayburn, S. W., Rosenbaum, M. S., Shirahada, K., and Williams, J. D. (2013). Transformative service research: An agenda for the future. Journal of Business Research, 66(8), 1203-1210.

Anselmsson, J., \& Johansson, U. (2007). Corporate social responsibility and the positioning of grocery brands: An exploratory study of retailer and manufacturer brands at point of purchase. International Journal of Retail \& Distribution Management, 35(10), 835-856.

Arnot, C., Boxall, P. C., \& Cash, S. B. (2006). Do ethical consumers care about price? A revealed preference analysis of fair trade coffee purchases. Canadian Journal of Agricultural Economics, 54(4), 555-565.

Auger, P., Burke, P., Devinney, T. M. \& Louviere, J. J. (2003). What will consumers pay for social product features? Journal of Business Ethics, 42(3), 281-304.

Baca-Motes, K., Brown, A., Gneezy, A., Keenan, E. A. \& Nelson, L. D. (2013). Commitment and behavior change: Evidence from the field. Journal of Consumer Research, 39(5), $1070-1084$

Bargh, J. A. \& Ferguson, M. J. (2000). Beyond behaviorism: on the automaticity of higher mental processes. Psychological Bulletin, 126(6), 925. 
Berger, J., \& Fitzsimons, G. (2008). Dogs on the street, pumas on your feet: How cues in the environment influence product evaluation and choice. Journal of Marketing Research, 45(1), 1-14.

Braun, K. A. (1999). Postexperience advertising effects on consumer memory. Journal of Consumer Research, 25(4), 319-334.

Campbell, M. C. (2007). “Says who?!” How the source of price information and affect influence perceived price (un) fairness. Journal of Marketing Research, 44(2), 261271.

Chandon, P., Morwitz, V. G. \& Reinartz, W. J. (2005), Do intentions really predict behavior? Self-generated validity effects in survey research, Journal of Marketing, 69(2), 1-14.

Cialdini, R. B. \& Goldstein, N. J. (2004). Social influence: Compliance and conformity. Annual Review Psychology, 55, 591-621.

Cialdini, R. B. (2008). Influence: Science and practice (5th ed.). Boston, MA: Allyn and Bacon.

Cialdini, R. B. (2009). We have to break up. Perspectives on Psychological Science, 4(1), 56.

Cohen, R. (2009). Global issues for breakfast: The banana industry and its problems. The Science Creative Quarterly. Published online 2009-06-12.

Davison, W. P. (1983). The third-person effect in communication. Public Opinion Quarterly, 47(1), 1-15.

d'Astous, A. \& Legendre, A. (2009). Understanding consumers' ethical justifications: A scale for appraising consumers' reasons for not behaving ethically. Journal of Business Ethics, 87(2), 255-268. 
De Bro, S. C., Campbell, S. M., \& Peplau, L. A. (1994). Influencing a Partner to Use a Condom: A College Student Perspective. Psychology of Women Quarterly, 18(2), $165-182$.

Dijksterhuis, A., \& Van Knippenberg, A. (1998). The relation between perception and behavior, or how to win a game of Trivial Pursuit. Journal of Personality and Social Psychology, 74(4), 865.

Dijksterhuis, A., Smith, P. K., Van Baaren, R. B., \& Wigboldus, D. H. (2005). The unconscious consumer: Effects of environment on consumer behavior. Journal of Consumer Psychology, 15(3), 193-202.

Duhigg, C. (2014). The Power of Habit. London: Random House Group.

Freestone, O. M. \& McGoldrick, P. J. (2008). Motivations of the ethical consumer. Journal of Business Ethics, 79(4), 445-467.

Friestad, M. \& Wright, P. (1994). The persuasion knowledge model: How people cope with persuasion attempts. Journal of Consumer Research, 21(1), 1-31.

Fogelberg, C. (2008). På väg mot miljöanpassade kostråd [Towards greener food consumption]. Sweden: National Foods Administration, rapport 9.

Fogg, B. J. (2002). Persuasive technology: Using computers to change what we think and do (interactive technologies). Burlington, MA: Morgan Kaufmann.

Fombelle, P. W., Sirianni, N. J., Goldstein, N. J. \& Cialdini, R. B. (2015). Let them all eat cake: Providing VIP services without the cost of exclusion for non-VIP customers. Journal of Business Research, 68(9), 1987-1996.

Grimmer, M., Kilburn, A. P., \& Miles, M. P. (2015). The effect of purchase situation on realized pro-environmental consumer behavior. Journal of Business Research, 69(5), 1582-1586. 
Griskevicius, V., Tybur, J. M. \& Van den Bergh, B. (2010). Going green to be seen: status, reputation, and conspicuous conservation. Journal of Personality and Social Psychology, 98(3), 392.

Gupta, S. \& Ogden, D. T. (2009). To buy or not to buy? A social dilemma perspective on green buying. Journal of Consumer Marketing, 26(6), 376-391.

Hainmueller, J. \& Hiscox, M. J., The Socially Conscious Consumer? Field Experimental Tests of Consumer Support for Fair Labor Standards (2015). MIT Political Science Department Research Paper No. 2012-15.

Halpern, D. (2015). Inside the Nudge Unit. London: WH Allen.

Hartline, M. D., \& Jones, K. C. (1996). Employee performance cues in a hotel service environment: Influence on perceived service quality, value, and word-of-mouth intentions. Journal of Business Research, 35(3), 207-215.

He, Y., Chen, Q., \& Alden, D. L. (2012). Consumption in the public eye: The influence of social presence on service experience. Journal of Business Research, 65(3), 302310.

Herr, P. M. (1989). Priming price: Prior knowledge and context effects. Journal of Consumer Research, 16(1), 67-75.

Hill, K. M., Fombelle, P. W., \& Sirianni, N. J. (2016). Shopping under the influence of curiosity: How retailers use mystery to drive purchase motivation. Journal of Business Research, 69(3), 1028-1034.

Hiscox, M. \& Smyth, N. (2006). Is there Consumer Demand for Improved Labor Standards? Evidence from Field Experiments in Social Product Labeling. Harvard University: Cambridge MA. 
Huguet, P. \& Régner, I. (2009). Counter-stereotypic beliefs in math do not protect school girls from stereotype threat. Journal of Experimental Social Psychology, 45(4), 1024-1027.

Janiszewski, C., \& Wyer Jr., R. S. (2014). Content and process priming: A review. Journal of Consumer Psychology, 24(1), 96-118.

Janssen, L., Fennis, B. M., Pruyn, A. T. H., \& Vohs, K. D. (2008). The path of least resistance: Regulatory resource depletion and the effectiveness of social influence techniques. Journal of Business Research, 61(10), 1041-1045.

Kirmani, A., \& Rao, A. R. (2000). No pain, no gain: A critical review of the literature on signaling unobservable product quality. Journal of Marketing, 64(2), 66-79.

Krishna, A. (1992). The normative impact of consumer price expectations for multiple brands on consumer purchase behavior. Marketing Science, 11(3), 266-286.

Langer, E. J., Blank, A. \& Chanowitz, B. (1978). The mindlessness of ostensibly thoughtful action: The role of "placebic" information in interpersonal interaction. Journal of Personality and Social Psychology, 36(6), 635-642.

Légal, J. B., Chappé, J., Coiffard, V., \& Villard-Forest, A. (2012). Don't you know that you want to trust me? Subliminal goal priming and persuasion. Journal of Experimental Social Psychology, 48(1), 358-360.

Levitt, S. D. \& List, J. A. (2007). What do laboratory experiments measuring social preferences reveal about the real world? Journal of Economic Perspectives, 21(2), 153-174.

Levitt, S. D. \& List, J. A. (2009). Field experiments in economics: The past, the present, and the future. European Economic Review, 53(1), 1-18. 
Lindström, A., Berg, H., Nordfält, J., Roggeveen, A. L., \& Grewal, D. (2016). Does the presence of a mannequin head change shopping behavior? Journal of Business Research, 69(2), 517-524.

Loureiro, M. L., McCluskey, J. J. \& Mittelhammer, R. C. (2002). Will consumers pay a premium for eco-labeled apples? Journal of Consumer Affairs, 36(2), 203-219.

MacGillivray, A. (2000). The fair share - The growing market share of green and ethical products. London: New Economics Foundation.

McCabe, M. P. \& Ricciardelli, L. A. (2005). A prospective study of pressures from parents, peers, and the media on extreme weight change behaviors among adolescent boys and girls. Behaviour Research and Therapy, 43(5), 653-668.

Milgram, S. (1975). Obedience to authority. New York: Harper Torchbooks.

Mintel (2006). Green living (US Marketing Research Report). London.

Moon, H., \& Conlon, D. E. (2002). From acclaim to blame: evidence of a person sensitivity decision bias. Journal of Applied Psychology, 87(1), 33.

Motes, W. H., \& Woodside, A. G. (2001). Purchase experiments of extra-ordinary and regular influence strategies using artificial and real brands. Journal of Business Research, 53(1), 15-35.

Pham, M. T. (2013). The seven sins of consumer psychology. Journal of Consumer Psychology, 23(4), 411-423.

Peattie, K. (2010). Green consumption: behavior and norms. Annual Review of Environment and Resources, 35(1), 195.

Pratt, M. G., \& Rafaeli, A. (1997). Organizational dress as a symbol of multilayered social identities. Academy of Management Journal, 40(4), 862-898. 
Robertson, L. S., Kelley, A. B., O'Neill, B., Wixom, C. W., Eiswirth, R. S., \& Haddon Jr., W. (1974). A controlled study of the effect of television messages on safety belt use. American Journal of Public Health, 64(11), 1071-1080.

Scamel-Katz S. (2012). The Art of Shopping. LID Publishing: London.

Siegel, M., \& Biener, L. (2000). The impact of an antismoking media campaign on progression to established smoking: results of a longitudinal youth study. American Journal of Public Health, 90(3), 380.

Sorensen H. (2009). Inside the Mind of the Shopper. Pearson: New Jersey.

Spangenberg, E. R., Greenwald, A. G., \& Sprott, D. E. (2008). Will you read this article's abstract? Theories of the question-behavior effect. Journal of Consumer Psychology, 18(2), 102-106.

Spangenberg, E. R., Sprott, D. E., Grohman, B. \& Smith, R. J. (2003), Mass-communicated prediction requests: Practical application and a cognitive dissonance explanation for self-prophecy. Journal of Marketing, 67(3), 47-62.

Spangenberg, E. R., Sprott, D. E., Grohmann, B., \& Tracy, D. L. (2006). Gender-congruent ambient scent influences on approach and avoidance behaviors in a retail store. Journal of Business Research, 59(12), 1281-1287.

Sprott, D. E., Spangenberg, E. R., Block, L. G., Fitzsimons, G. J., Morwitz, V. G. \& Williams, P. (2006). The question-behavior effect: What we know and where we go from here. Social Influence, 1(2), 128-137.

Stolle, D. \& M. Micheletti. 2005. The Gender Gap Reversed. In B. O'Neill and E. Gidengil (eds), Gender and Social Capital. London: Routledge.

Sutton, R. I. \& Rafaeli, A. (1988). Untangling the relationship between displayed emotions and organizational sales: The case of convenience stores. Academy of Management Journal, 31(3), 461-487. 
Swedish Consumer Agency, (2006). Ekologiska livsmedel - ett strategiunderlag för livsmedelsbranschen [Ecological food - a strategy for the retail food industry]. Karlstad: Report 2006:13.

Söderlund, M. (2016). Employee mere presence and its impact on customer satisfaction. Psychology \& Marketing, 33(6), 449-464.

Söderlund, M., \& Mattsson, J. (2015). Merely asking the customer to recommend has an impact on word-of-mouth activity. Journal of Retailing and Consumer Services, 27, 80-89.

Thaler, R. H. (2015). Misbehaving. WW Norton \& Co.

Thaler, R. H. \& Sunstein, C. R. (2008). Nudge: Improving decisions about health, wealth, and happiness. New Haven, CT: Yale University Press.

Tybout, A. M. \& Yalch, R. F. (1980). The effect of experience: A matter of salience? Journal of Consumer Research, 6(4), 406-413.

Verbeke, W., Bagozzi, R. P., \& Belschak, F. D. (In Press). The role of status and leadership style in sales contests: A natural field experiment. Journal of Business Research.

Vermeir, I. \& Verbeke, W. (2006). Sustainable food consumption: Exploring the consumer "attitude-behavioral intention" gap. Journal of Agricultural and Environmental Ethics, 19(2), 169-194.

Wilkinson, T. M. (2013). Nudging and manipulation. Political Studies, 61(2), 341-355.

Williams, P., Block, L. G., \& Fitzsimons, G. J. (2006). Simply asking questions about health behaviors increases both healthy and unhealthy behaviors. Social Influence, 1(2), $117-127$.

Wilson, M. D., Kastrinakis, M., Angelo, L. J., \& Getson, P. (1994). Attitudes, knowledge, and behavior regarding condom use in urban black adolescent males. Adolescence, 29(113), 13. 
Young, W., Hwang, K., McDonald, S. \& Oates, C. J. (2010). Sustainable consumption: Green consumer behavior when purchasing products. Sustainable Development, 18(1), $20-31$.

Zeithaml, V. A. (1988). Consumer perceptions of price, quality, and value: a means-end model and synthesis of evidence. Journal of Marketing, 52(3), 2-22. 


\section{Figures and Tables to be inserted}

Table 1. Means and standard deviations for the perceived likelihood that the four respective influence strategies would change consumer behavior $(n=200)$.

\begin{tabular}{|l|c|c|}
\hline Influence strategy & $\boldsymbol{M}$ & SD \\
\hline Signaling & 5.41 & 2.32 \\
\hline Labeling & 4.91 & 2.04 \\
\hline Price & 7.81 & 1.63 \\
\hline
\end{tabular}


Table 2. Verbal influence strategies used in Study I $(n=400)$.

\begin{tabular}{|l|l|}
\hline Name and theoretical background & Verbal influence script \\
\hline Question-behavior (Sprott et al., 2006) & "Are you going to buy bananas? We have \\
environment friendly labeled and non- \\
environment friendly bananas right over there \\
[pointing at the banana desk]."
\end{tabular}




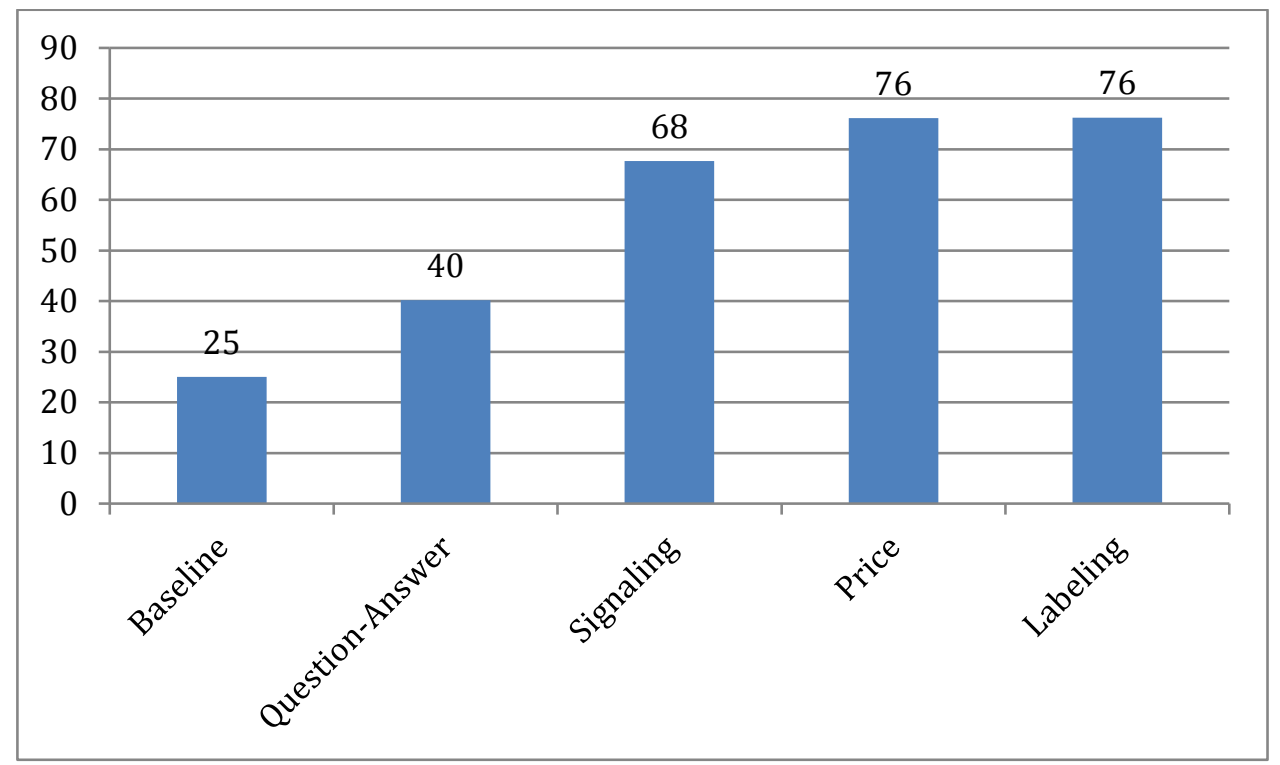

Figure 1. Proportion of choices to purchase ecological bananas under the four experimental conditions (Question-behavior, Signaling, Price, and Labeling), and Baseline. 
Table 3. Written influence strategies printed on the signs used in Study II $(n=400)$.

\begin{tabular}{|l|l|}
\hline Name and theoretical background & Information on sign \\
\hline Signaling (Griskevicious et al., 2012) & $\begin{array}{l}\text { Looking for bananas? “We are currently measuring } \\
\text { the amount of ecological bananas people are } \\
\text { buying." }\end{array}$ \\
\hline Labeling (Tybout \& Yalch, 1980) & $\begin{array}{l}\text { Looking for bananas? “Hello environmentalist, our } \\
\text { ecological bananas are right here." }\end{array}$ \\
\hline Price (Arnot et al., 2006; Young et al., 2012; and & Looking for bananas? “Ecological bananas are the \\
others cited above) & same price as competing brands." \\
\hline
\end{tabular}




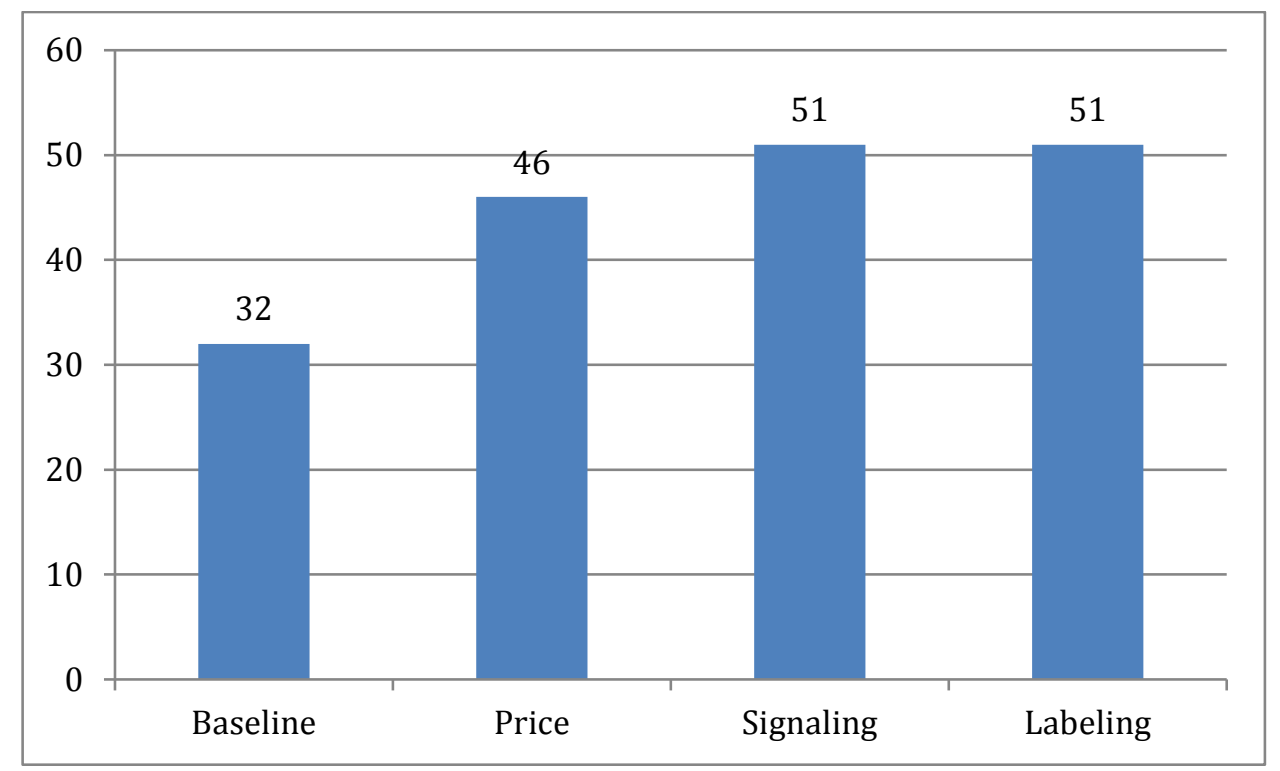

Figure 2. Proportion of ecological choices under the three experimental conditions (Price, Signaling, and Labeling), and the baseline condition. 